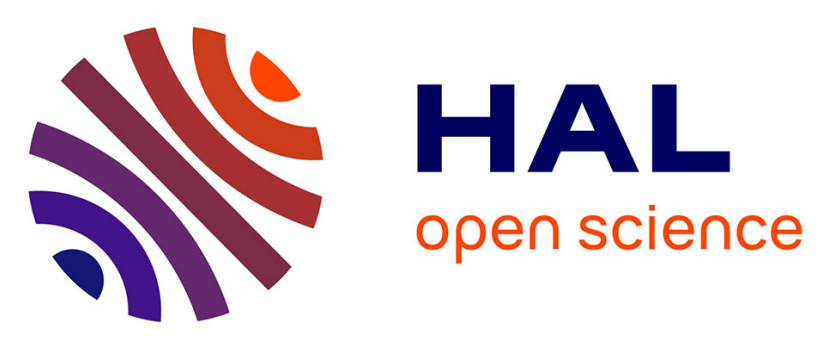

\title{
Occupational use of high-level disinfectants and asthma incidence in early- to mid-career female nurses: a prospective cohort study
}

Orianne Dumas, Audrey J Gaskins, Krislyn M Boggs, Scott A Henn, Nicole Le Moual, Raphäelle Varraso, Jorge E Chavarro, Carlos Camargo Jr

\section{To cite this version:}

Orianne Dumas, Audrey J Gaskins, Krislyn M Boggs, Scott A Henn, Nicole Le Moual, et al.. Occupational use of high-level disinfectants and asthma incidence in early- to mid-career female nurses: a prospective cohort study. Occupational and Environmental Medicine, 2021, pp.oemed-2020-106793. 10.1136/oemed-2020-106793 . inserm-03166970

\section{HAL Id: inserm-03166970 https://www.hal.inserm.fr/inserm-03166970}

Submitted on 11 Mar 2021

HAL is a multi-disciplinary open access archive for the deposit and dissemination of scientific research documents, whether they are published or not. The documents may come from teaching and research institutions in France or abroad, or from public or private research centers.
L'archive ouverte pluridisciplinaire HAL, est destinée au dépôt et à la diffusion de documents scientifiques de niveau recherche, publiés ou non, émanant des établissements d'enseignement et de recherche français ou étrangers, des laboratoires publics ou privés. 
Occupational use of high-level disinfectants and asthma incidence in early to midcareer female nurses: a prospective cohort study

Orianne Dumas ${ }^{1}$, Audrey J Gaskins ${ }^{2,3,4}$, Krislyn M. Boggs ${ }^{3,5}$, Scott A Henn ${ }^{6}$, Nicole Le Moual $^{1}$, Raphaëlle Varraso ${ }^{1}$, Jorge E Chavarro ${ }^{2,3,7}$, Carlos A Camargo Jr ${ }^{3,5,7}$

1. Université Paris-Saclay, UVSQ, Univ. Paris-Sud, Inserm, Équipe d'Épidémiologie respiratoire intégrative, CESP, 94807, Villejuif, France

2. Department of Nutrition, Harvard TH Chan School of Public Health, Boston, MA, USA

3. Channing Division of Network Medicine, Department of Medicine, Brigham \& Women's Hospital and Harvard Medical School, Boston, MA, USA

4. Department of Epidemiology, Rollins School of Public Health, Emory University, Atlanta, GA

5. Department of Emergency Medicine, Massachusetts General Hospital and Harvard Medical School, Boston, MA, USA

6. National Institute for Occupational Safety and Health, Centers for Disease Control and Prevention, Cincinnati, OH, USA

7. Department of Epidemiology, Harvard TH Chan School of Public Health, Boston, MA, USA.

\section{Correspondence}

Orianne Dumas

Inserm, CESP, Équipe d'Épidémiologie respiratoire integrative

16, avenue Paul Vaillant Couturier 
94807 Villejuif cedex

France

e-mail: orianne.dumas@inserm.fr

Phone: (33) 145595357

Word count: 1818

\section{Key messages}

\section{What is already known about this subject?}

Occupational use of high-level disinfectants (HLDs) among healthcare workers has been associated with asthma. However, most studies are cross-sectional and results from longitudinal studies on asthma incidence are not entirely consistent.

\section{What are the new findings?}

In a prospective study of 17,280 early to mid-career female nurses (mean age: 34 years), in the US and Canada, followed-up over $\sim 4$ years, we found that occupational use of HLD among nurses was associated with significantly increased risk of developing asthma.

How might this impact on policy or clinical practice in the foreseeable future?

Our results add longitudinal evidence to an association between occupational exposure to disinfectants and asthma incidence and encourage the development of asthma prevention strategies compatible with infection control in healthcare settings. 


\begin{abstract}
Objectives: Occupational use of disinfectants among healthcare workers has been associated with asthma. However, most studies are cross-sectional and longitudinal studies are not entirely consistent. To limit the healthy worker effect, it is important to conduct studies among early to mid-career workers. We investigated the prospective association between use of disinfectants and asthma incidence in a large cohort of early to mid-career female nurses.

Methods: The Nurses' Health Study 3 is an ongoing, prospective, internet-based cohort of female nurses in the United States and Canada (2010-present). Analyses included 17,280 participants without history of asthma at study entry (mean age: 34 years) and who had completed $\geq 1$ follow-up questionnaire (sent every 6 months). Occupational use of high-level disinfectants (HLDs) was evaluated by questionnaire. We examined the association between HLD use and asthma development, adjusted for age, race, ethnicity, smoking status, and body mass index.
\end{abstract}

Results: During 67,392 person-years of follow-up, 391 nurses reported incident cliniciandiagnosed asthma. Compared to nurses who reported $\leq 5$ years of HLD use (89\%), those with $>5$ years of HLD use (11\%) had increased risk of incident asthma (adjusted hazard ratio [95\%CI], 1.38 [1.03-1.85]). The risk of incident asthma was elevated but not statistically significant in those reporting $>5$ years of HLD use and current use of $\geq 2$ products $(1.72$ [0.883.34]); asthma risk was significantly elevated in women with $>5$ years of HLD use but no current use (1.46 [1.00-2.12]).

Conclusions: Occupational use of high-level disinfectants was prospectively associated with increased asthma incidence in early to mid-career nurses.

Word count: 250 


\section{INTRODUCTION}

Disinfectants and cleaning products (DCPs) are widely used in the healthcare industry to protect patients and workers against healthcare-related infections [1]. In addition to ‘common' DCPs, specific chemicals are used for high-level disinfection of critical or semicritical items (e.g., surgical instruments, endoscopes), including aldehydes (e.g., glutaraldehyde), peracetic acid or hydrogen peroxide [2].

Evidence for adverse health effects of exposure to DCPs has grown in the last two decades [3,4]. Many studies have reported an association between these exposures and poor respiratory health, including asthma symptoms and poor asthma control $[3,5,6]$. However, most of these studies are cross-sectional, and results from longitudinal studies on asthma incidence are not entirely consistent. Three longitudinal population-based studies in Europe have reported associations between occupational exposure to DCPs and asthma incidence [79]. In contrast, in a longitudinal cohort of late-career nurses from the Nurses' Health Study II, no association was observed between exposure to DCPs and asthma incidence, potentially because of a healthy worker effect [10]. To limit this bias, it is important to actively follow-up workers from the beginning of their careers. Therefore, we investigated the prospective association between use of high-level disinfectants (HLDs) and incident asthma in a large cohort of early to mid-career female nurses in North America.

\section{METHODS}

The Nurses' Health Study 3 (NHS3) is an ongoing, prospective, internet-based open cohort of nurses in the US and Canada [11]. Female nurses (registered nurse, licensed practical/vocational nurse or nursing student) born on or after 1 January 1965 were eligible for the study. From 2010 to 2018, 46167 nurses enrolled in the study. Follow-up 
questionnaires are sent every 6 months. The Institutional Review Board of the Brigham and Women's Hospital (Boston, Massachusetts) approved the study. Completion of the web-based questionnaires implied informed consent.

Occupational use of HLD was evaluated in the baseline questionnaire [12]. Participants were first asked if they had ever used HLDs ("'In your career, have you ever used disinfectants to disinfect medical instruments, devices or supplies [such as endoscopes, thermometers or other items which cannot be sterilized] by either manual or automatic methods? (This does not include the cleaning of countertops or other surfaces)"). The questionnaire then listed several examples of disinfectants. Participants were also asked to report the duration of use during the career, and the type of HLD (e.g., aldehydes, hydrogen peroxide) used in the past month for disinfecting medical instruments. Finally, women reporting use of HLD in the past month were asked about the frequency of protective equipment use (never, sometimes, always) when handling HLDs, including disinfection system with dedicated local exhaust ventilation or respiratory protection (not including a surgical mask).

At baseline, participants were asked if they ever had clinician-diagnosed asthma. In follow-up questionnaires, they were asked to report clinician-diagnosed illnesses that they had in the past 12 months, including asthma. Incident asthma was defined by absence of asthma at baseline and report of new clinician-diagnosis of asthma in follow-up questionnaires. Information on potential confounders was assessed on the baseline questionnaire, including age, race/ethnicity, height, weight, and smoking history.

Associations between occupational use of HLD and asthma incidence was evaluated by Cox proportional hazard models, adjusted for age, race (white, black, other), ethnicity (Hispanic vs non-Hispanic), smoking habits (non-smoker, ex-smoker or current smoker) and body mass index (BMI, $<25,25-29.9, \geq 30 \mathrm{~kg} / \mathrm{m} 2$ ). As we hypothesized that conducting 
analyses in a group of early career nurses would help minimize a potential healthy worker effect, we performed an age-stratified analysis using median age (34 years) as the cut-off.

\section{RESULTS}

Among the 46,167 NHS3 participants, 35,119 were employed full-time in nursing at baseline. Among them, 769 women with missing data for HLD use or potential confounders, and 6,895 women who reported asthma diagnosis before or at baseline, were excluded. Among the 27,455 women without asthma at baseline, follow-up data were available for 17,280 (63\%), who were eligible for the current analysis (online supplementary Figure E1).

At baseline, participants were on average 34 years old (range 20-52 years; age did not differ according to asthma status, $\mathrm{p}=0.14) ; 93 \%$ were white, $19 \%$ were current smokers and $5 \%$ were ex-smokers. Regarding HLD use, $16 \%$ of the nurses reported $1-5$ years of use, and $11 \%$ reported $>5$ years of use, in their career until baseline. Nurses reporting $>5$ years of HLD use were older, more often ex- or current-smokers and more often had BMI $\geq 30 \mathrm{~kg} / \mathrm{m} 2$ (online supplementary Table E1). Among 800 (5\%) nurses reporting current HLD use at baseline (at least $1 \mathrm{~h}$ per week in past month), 17\% reported using a disinfection system with dedicated ventilation and $13 \%$ reported using respiratory protection sometimes or always.

During 67,392 person-years of follow-up (mean follow-up: 3.8 years), 391 nurses reported incident clinician-diagnosed asthma. In multivariable models, nurses who reported 15 years of HLD use did not differ from nurses who reported never using HLD or $<1$ year of use (Table 1). In contrast, nurses who reported $>5$ years of HLD use had a significantly increased risk of incident asthma (adjusted hazard ratio [95\% CI], 1.38 [1.03-1.85]).

We examined the number and type of HLDs currently used among nurses with $>5$ years of HLD use, using as reference group nurses who never used HLD or had $\leq 5$ years of use. The risk of incident asthma was elevated but not statistically significant in those reporting 
current use of $\geq 2$ products $(1.72[0.88-3.34])$. The risk of incident asthma was significantly increased in women with $>5$ years of HLD use but no current use (1.46 [1.00-2.12]). When examining the types of HLDs (Table 1) or use of protective equipment (online supplementary Table E2) in the past month, effect estimates were imprecise due to low numbers and we observed no significant associations. Statistical power also was limited for the age-stratified analysis (online supplementary Table E3) but we observed the association between $>5$ years of HLD use (vs. never or $\leq 5$ years) and incident asthma among the nurses $<34$ years old at baseline (1.75 [1.03-2.98]) and not among the older nurses (1.27 [0.90-1.78]; $\left.\mathrm{P}_{\text {inter }}=0.23\right)$.

\section{DISCUSSION}

We found that occupational use of HLD among US and Canadian female nurses was associated with increased risk of developing asthma. These findings are based on a prospective study of 17,280 early to mid-career nurses (mean age: 34 years) with a mean follow-up time of $\sim 4$ years.

Our results are consistent with many cross-sectional and a few longitudinal studies on disinfectants and cleaning products (DCPs) [3]. Three European cohorts reported a prospective association of occupational exposure to DCPs with increased risk of asthma development [7-9], although none of these studies specifically examined the role of HLDs. In contrast, in a longitudinal study in an older population (aged 55 years at baseline on average), drawn from a related cohort of US registered nurses, we did not observe any association between current occupational exposure to DCPs, including HLDs, and asthma incidence [10]. We hypothesized that this result was due to a healthy worker survivor effect, as the study selected women free of asthma after several decades in nursing, and, therefore, likely excluded the most susceptible individuals. In the current study of early- to mid-career nurses, 
despite the significant association between HLD use and asthma incidence, sensitivity analyses also hinted a healthy worker effect. First, although the association with asthma incidence was observed for duration of HLD use $>5$ years, it was only observed among younger nurses ( $\leq 33$ years old at baseline) in analyses stratified by age group, where age is considered as a surrogate for the number of years in nursing. Second, when examining the number of products used currently in addition to duration of use, the association was only observed for nurses with no current use of HLD at baseline. These findings emphasize the challenge of addressing the healthy worker effect, even in longitudinal studies. The literature suggests that respiratory health effects of DCPs should be investigated from very early career onward. Moreover, since workers may reduce the use of products before asthma diagnosis, complete exposure history is preferable.

The fact that the association between HLD use and asthma incidence was observed among nurses who no longer used HLD at baseline may also suggests that for many nurses, asthma diagnosis possibly occurred several years after reduction of exposure. In occupational asthma, an average duration of several years between first symptoms and diagnosis has been reported [13], and it is common that symptoms persist after exposure reduction or cessation [14]. In addition, HLD are thought to cause asthma predominantly through an irritant mechanism [3], and irritant-induced occupational asthma is particularly difficult to diagnose [15]. Thus, our results may reflect a delayed diagnosis or under-diagnosis of irritant-induced occupational asthma in nurses.

In our study, asthma was defined based on a single question on clinician-diagnosed asthma at baseline and in follow-up questionnaires, which is a limitation. However, the validity of self-reported health outcomes in cohorts of nurses is generally high [16]. Moreover, in analyses conducted in a similar nursing cohort in which more detailed information on asthma was collected, results were unchanged regardless of the asthma 
definition (single question or a refined definition based on supplementary questionnaires) [17]. Occupational use of HLD was also self-reported, which may raise questions regarding both differential and nondifferential exposure misclassification [18]. As history of HLD use was evaluated before the report of asthma diagnosis, differential recall bias is unlikely. However, the HLD use was only evaluated at baseline, and the use of specific products was evaluated in the past month, which may not reflect past exposure. Moreover, nurses may not know precisely the chemicals they use for high-level disinfection [18]. Thus, non-differential misclassification may have affected the analyses of duration of HLD use and specific HLDs, and driven associations toward the null. This may partly explain why no significant associations with asthma were observed in analyses of specific HLDs. In addition, the occupational questionnaire was not specifically designed to study risk factors for asthma [12]. Consequently, questions were limited to HLDs and a potential role of low/medium level DCPs in asthma could not be evaluated. Similarly, no information regarding the use of latex gloves was available in NHS3. However, our work in the Nurses' Health Study II [5] and other studies [19] suggest that latex exposure is no longer the major concern for respiratory health among healthcare workers, most likely because of the reduction in the use of powdered latex gloves.

The use of ventilation systems or respiratory protections when handling HLDs was relatively limited, as previously reported [2]. Low numbers prevented a meaningful analysis on their impact on the association between HLD use and asthma. Although elimination of hazardous substances is generally a preferred measure in the prevention of work-related asthma, the role of protective equipment in modulating asthma risk warrants further investigation.

In summary, our results add longitudinal evidence to an association between occupational exposure to disinfectants and asthma development, and encourage the 
development of asthma prevention strategies compatible with infection control in healthcare settings [1]. 


\section{Acknowledgments}

The Nurses' Health Study 3 is coordinated at Harvard T.H. Chan School of Public Health and the Channing Division of Network Medicine, Brigham and Women's Hospital - both located in Boston, MA, USA. We would like to thank the participants and staff of the Nurses' Health Study 3 for their valuable contributions. We also thank Christina C Lawson (National Institute for Occupational Safety and Health, Centers for Disease Control and Prevention, Cincinnati, Ohio, USA) for her participation in the creation of the occupational exposure questionnaires.

Authors' contributions: OD contributed to the study conception, the analysis and interpretation of the data, and primary manuscript preparation. AJG, SAH and JEC contributed to the acquisition and interpretation of the data and critical revision of the manuscript. KB, NLM, and RV were involved in the data interpretation and critical revision of the manuscript. CAC participated in the study conception, data interpretation and critical revision of the manuscript. All authors approved the final version of the manuscript and agreed to be accountable for all aspects of the work in ensuring that questions related to the accuracy or integrity of any part of the work are appropriately investigated and resolved.

Competing Interests: Dr. Camargo reports grants from NIOSH/CDC and NIH during the conduct of the study. Dr. Chavarro reports grants from National Institute of Occupational Safety and Health, grants from National Institute of Environmental Health Sciences, grants from National Heart, Lung and Blood Institute, during the conduct of the study.

\section{Funding}

National Institute for Occupational Safety and Health R01 OH-10359; National Institutes of Health R24-ES028521-01, and U01-HL145386-01. 


\section{Disclaimer}

The findings and conclusions in this report are those of the author(s) and do not necessarily represent the official position of the National Institute for Occupational Safety and Health, Centers for Disease Control and Prevention. 


\section{REFERENCES}

1 Quinn MM, Henneberger PK, Braun B, et al. Cleaning and disinfecting environmental surfaces in health care: Toward an integrated framework for infection and occupational illness prevention. Am J Infect Control 2015;43:424-34.

2 Henn SA, Boiano JM, Steege AL. Precautionary practices of healthcare workers who disinfect medical and dental devices using high-level disinfectants. Infect Control Hosp Epidemiol 2015;36:180-5.

3 Folletti I, Siracusa A, Paolocci G. Update on asthma and cleaning agents. Curr Opin Allergy Clin Immunol 2017;17:90-5.

4 Dumas O, Le Moual N. Damaging effects of household cleaning products on the lungs. Expert Rev Respir Med 2020;14:1-4.

5 Dumas O, Wiley AS, Quinot C, et al. Occupational exposure to disinfectants and asthma control in US nurses. Eur Respir J 2017;50:pii: 1700237.

6 Su FC, Friesen MC, Humann M, et al. Clustering asthma symptoms and cleaning and disinfecting activities and evaluating their associations among healthcare workers. Int $J$ Hyg Environ Health 2019;222:873-83.

7 Kogevinas M, Zock JP, Jarvis D, et al. Exposure to substances in the workplace and new-onset asthma: an international prospective population-based study (ECRHS-II). Lancet 2007;370:336-41.

8 Ghosh RE, Cullinan P, Fishwick D, et al. Asthma and occupation in the 1958 birth cohort. Thorax 2013;68:365-71.

9 Lillienberg L, Andersson E, Janson C, et al. Occupational Exposure and New-onset Asthma in a Population-based Study in Northern Europe (RHINE). Ann Occup Hyg 2013;57:482-92.

10 Dumas O, Boggs KM, Quinot C, et al. Occupational exposure to disinfectants and 
asthma incidence in U.S. nurses: A prospective cohort study. Am J Ind Med 2020;63:44-50. doi:10.1002/ajim.23067

11 Bao Y, Bertoia ML, Lenart EB, et al. Origin, Methods, and Evolution of the Three Nurses' Health Studies. Am J Public Heal 2016;106:1573-81.

12 Gaskins AJ, Chavarro JE, Rich-Edwards JW, et al. Occupational use of high-level disinfectants and fecundity among nurses. Scand J Work Environ Heal 2017;43:17180. doi:10.5271/sjweh.3623

13 Descatha A, Leproust H, Choudat D, et al. Factors associated with severity of occupational asthma with a latency period at diagnosis. Allergy 2007;62:795-801.

14 Rachiotis G, Savani R, Brant A, et al. Outcome of occupational asthma after cessation of exposure: a systematic review. Thorax 2007;62:147-52.

15 Vandenplas O, Wiszniewska M, Raulf M, et al. EAACI position paper: Irritant-induced asthma. Allergy 2014;69:1141-53.

16 Colditz GA, Martin P, Stampfer MJ, et al. Validation of questionnaire information on risk factors and disease outcomes in a prospective cohort study of women. Am J Epidemiol 1986;123:894-900.

17 Dumas O, Varraso R, Zock JP, et al. Asthma history, job type and job changes among US nurses. Occup Env Med 2015;72:482-8.

18 Donnay C, Denis M-A, Magis R, et al. Under-estimation of self-reported occupational exposure by questionnaire in hospital workers. Occup Env Med 2011;68:611-7.

19 Wiszniewska M, Walusiak-Skorupa J. Occupational allergy: respiratory hazards in healthcare workers. Curr Opin Allergy Clin Immunol 2014;14:113-8. 
Table 1 Prospective association between use of high-level disinfectants (HLDs) and asthma incidence in female nurses, $\mathrm{n}=17,820$

\begin{tabular}{|c|c|c|c|c|c|c|}
\hline & \multirow[t]{2}{*}{$\begin{array}{l}\text { Person- } \\
\text { years }\end{array}$} & \multirow[t]{2}{*}{$\begin{array}{l}\text { No. of } \\
\text { cases }\end{array}$} & \multicolumn{2}{|c|}{ Age-adjusted HR } & \multicolumn{2}{|c|}{$\begin{array}{l}\text { Multivariable- } \\
\text { adjusted HR }\end{array}$} \\
\hline & & & HR & $95 \% \mathrm{CI}$ & HR & $95 \% \mathrm{CI}$ \\
\hline \multicolumn{7}{|l|}{ Duration of HLD use } \\
\hline Never or $<1$ year (ref.) & 48,100 & 276 & 1 & - & 1 & - \\
\hline $1-5$ years & 10,247 & 58 & 0.98 & $0.74-1.30$ & 0.96 & $0.73-1.28$ \\
\hline$>5$ years & 6,761 & 57 & 1.42 & $1.06-1.90$ & 1.38 & $1.03-1.85$ \\
\hline Never or $\leq 5$ years (ref.) & 58,347 & 334 & 1 & - & 1 & - \\
\hline$>5$ years & 6,761 & 57 & 1.42 & 1.07-1.90 & 1.39 & $1.04-1.86$ \\
\hline \multicolumn{7}{|c|}{ Duration of HLD use and number of HLDs currently* used } \\
\hline Never or $\leq 5$ years (ref.) & 58,347 & 334 & 1 & - & 1 & - \\
\hline \multicolumn{7}{|l|}{$>5$ years of use } \\
\hline No current use & 3,540 & 31 & 1.48 & 1.01-2.15 & 1.46 & $1.00-2.12$ \\
\hline Current use of 1 HLD & 2,357 & 17 & 1.22 & $0.75-1.99$ & 1.17 & $0.72-1.92$ \\
\hline Current use of $\geq 2$ HLDs & 864 & 9 & 1.77 & $0.91-3.45$ & 1.72 & $0.88-3.34$ \\
\hline \multicolumn{7}{|c|}{ Duration of HLD use and type of HLDs currently* used } \\
\hline Never or $\leq 5$ years (ref.) & 58,347 & 334 & 1 & - & 1 & - \\
\hline \multicolumn{7}{|l|}{$>5$ years of use } \\
\hline Glutaraldehyde* & 1869 & 18 & 1.61 & $1.00-2.59$ & 1.55 & $0.96-2.49$ \\
\hline Ortho-phtalaldehyde* & 529 & 4 & 1.24 & $0.46-3.34$ & 1.20 & $0.44-3.22$ \\
\hline Peracetic acid*† & 400 & 1 & - & - & - & - \\
\hline Hydrogen peroxide* & 841 & 9 & 1.79 & $0.92-3.48$ & 1.73 & $0.89-3.37$ \\
\hline Other* & 574 & 4 & 1.17 & $0.44-3.13$ & 1.12 & $0.42-3.01$ \\
\hline
\end{tabular}

Abbreviations: HR, hazard ratio; CI, confidence interval; HLD, high-level disinfectant.

Multivariable models were adjusted for age, race, ethnicity, smoking status and body mass index.

Use of HLD was evaluated by questionnaire at baseline.

Results in boldface are statistically significant.

* In the past month.

$\dagger$ HR not calculated because of low number of exposed cases. 